\title{
High-Performance Planar Thin Film Thermochromic Window via Dynamic Optical Impedance Matching
}

\author{
Christian Sol, Mark Portnoi, Tao Li, Kargal L. Gurunatha, Johannes Schläfer, Stefan Guldin, \\ Ivan P. Parkin, and Ioannis Papakonstantinou*
}

Cite This: https://dx.doi.org/10.1021/acsami.9b18920

Read Online

ACCESS |

山ll Metrics \& More

Article Recommendations

Supporting Information

ABSTRACT: Window coatings with dynamic solar transmittance represent an excellent opportunity to reduce building heating and cooling loads, which account for $>40 \%$ of energy consumed by the built environment. In particular, inorganic vanadium dioxide-based thermochromic coatings offer long lifetimes (>30 years) and can be passively integrated into a window system without additional electronics or power requirements. However, their limited solar modulation depth and wide phasechange hysteresis have traditionally restricted their ability to adapt to changing weather conditions. Here, we derive an optical performance limit for thin film vanadium dioxide coatings, which we find to be far beyond the current literature. Furthermore, we experimentally demonstrate a solution-processed multilayer thin film coating that uses temperature-dependent optical impedance matching to approach the optical performance limit. The thin film coating demonstrated has a record solar transmittance modulation of $21.8 \%$ while maintaining a high level of visible transparency $(\sim 50 \%)$ and minimal hysteresis $\left(\sim 10^{\circ} \mathrm{C}\right)$. This work represents a step-change in thin film thermochromic window coatings and, as a result, establishes planar thin film vanadium dioxide as the most viable morphology for high-performance thermochromic windows.

KEYWORDS: vanadium dioxide, thermochromic, energy-efficient glazing, smart windows, optical coatings, thin films, dynamic solar control coatings

\section{INTRODUCTION}

Reducing energy consumption is vital to reducing $\mathrm{CO}_{2}$ emissions and global warming. ${ }^{1,2}$ Heating and cooling loads account for $>40 \%$ of energy consumed within the built environment, ${ }^{3}$ and window coatings with dynamic solar transmittance represent an excellent opportunity to reduce this load. ${ }^{4-6}$ In particular, inorganic vanadium dioxide-based thermochromic coatings offer long lifetimes ( $>30$ years $^{7}$ ) and can be passively integrated into a window system without additional electronics or power requirements. ${ }^{8-10}$ The basic principle of a vanadium dioxide $\left(\mathrm{VO}_{2}\right)$ dynamic window coating is that in its low-temperature monoclinic $\mathrm{VO}_{2}(\mathrm{M})$ state, the coating is highly transparent to solar radiation, whereas in its high-temperature rutile $\mathrm{VO}_{2}(\mathrm{R})$ state, solar transmittance is reduced significantly, ${ }^{11}$ such that the dynamic window passively regulates solar heat gain in response to changing seasonal conditions. ${ }^{12}$ There are a number of fundamental material challenges associated with the performance of vanadium dioxide in dynamic window coatings, and progress in solving these challenges has most recently been reviewed by Faucheu et al. ${ }^{13}$ and Chang et al. ${ }^{9}$ Broadly, these challenges can be split into two categories: transition based, that is, the temperature-dependent hysteretic response of the coating, and the optical properties, that is, visible transparency and solar modulation ability. It is interesting to note that much of the early work investigating vanadium dioxide as a window coating material focused on using thin film deposition methods, such as sputtering ${ }^{14,15}$ or chemical vapor deposition, ${ }^{11,16-18}$ both of which can be implemented in large-scale manufacturing; ${ }^{19,20}$ however, a significant drawback of thin film vanadium dioxide as a dynamic window coating material is that changes in solar absorption and reflectance typically oppose each other, ${ }^{11,21-27}$ which dramatically reduces solar modulation ability. Nanoparticle-based coatings have been shown to improve the solar modulation because of reduced reflectivity and also because they exhibit a plasmon resonance in the high-temperature metallic state, which enhances attenuation around $1000 \mathrm{~nm}$ where solar intensities are relatively high. ${ }^{28-30}$ However, $\mathrm{VO}_{2}$ coatings that utilize nanoscale features have other issues, such as significant phase-change hysteresis seen when particle domain sizes are small, $7,13,29-31$ which greatly reduces energy-saving performance $^{32-34}$ as well as significant scattering and optical haze when larger nanoparticles are used. ${ }^{28}$ In this work, we rigorously derive and examine the optical constants of vanadium dioxide and find that the opposing changes in reflectance and absorption of thin film vanadium dioxide are a direct result of the opposing changes in the refractive index and

Received: October 19, 2019

Accepted: January 30, 2020

Published: January 30, 2020 
(a)

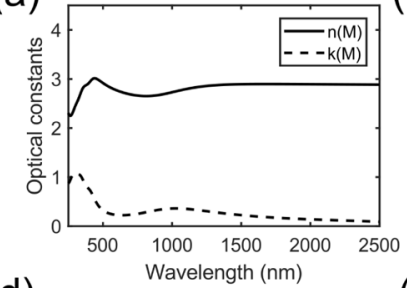

(d)

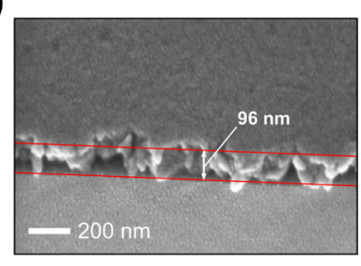

(b)

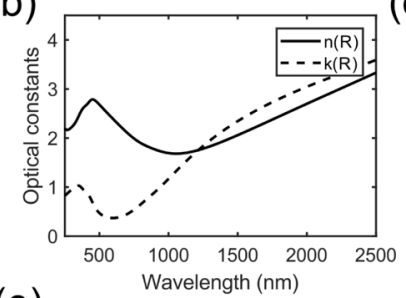

(e)

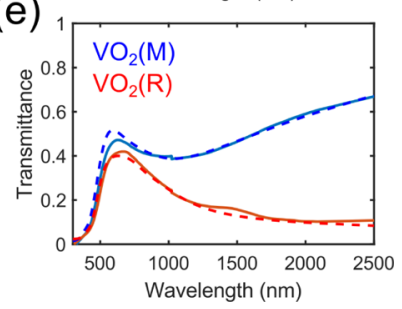

(c)

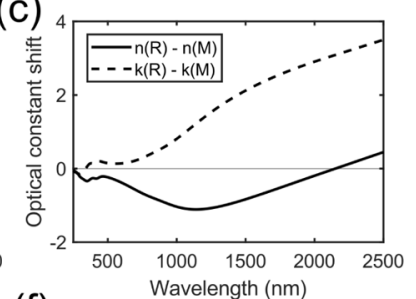

(f)

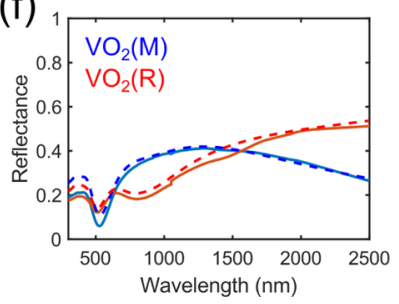

Figure 1. Optical constants of vanadium dioxide. (a) Optical constants of low-temperature $\left(21^{\circ} \mathrm{C}\right) \mathrm{VO}_{2}(\mathrm{M})$. (b) Optical constants of hightemperature $\mathrm{VO}_{2}(\mathrm{R})$. (c) Low-temperature optical constants subtracted from high-temperature optical constants. (d) Side-on electron microscopy image of the measured $\mathrm{VO}_{2}$ thin film. (e,f) Measured and simulated reflectance and transmittance of $96 \mathrm{~nm}$ thick vanadium dioxide.

extinction coefficient that occur as a result of the thermochromic transition. In light of this, we present an alternative approach based on optical impedance matching in thin films, where the opposing changes in optical constants are no longer detrimental to solar modulation but rather taken advantage of in the optical design of the coating.

\section{RESULTS}

2.1. Thin Film Optical Constants. In Figure $1 \mathrm{a}, \mathrm{b}$ the optical constants are shown for $\mathrm{VO}_{2}(\mathrm{M})$ and $\mathrm{VO}_{2}(\mathrm{R})$, respectively, whereas Figure 1c shows the shift in optical constants between low-temperature $\mathrm{VO}_{2}(\mathrm{M})$ and high-temperature $\mathrm{VO}_{2}(\mathrm{R})$. We observe that, as a result of the transition, the extinction coefficient increases across all solar wavelengths; conversely, for the refractive index, increases are seen only at longer wavelengths $(>2000 \mathrm{~nm})$, whereas decreases are seen below this wavelength (see Figure 1c). These opposing changes in the extinction coefficient and refractive index explain why absorption and reflectance are typically found to oppose each other in thin films. ${ }^{11,21-26}$ The optical constants of $\mathrm{VO}_{2}(\mathrm{M})$ and $\mathrm{VO}_{2}(\mathrm{R})$ were obtained via ellipsometry with the fitted thickness of $96 \mathrm{~nm}$, as confirmed by scanning electron microscopy (SEM, see Figure 1d). The measured ellipsometric parameters and the corresponding theoretical fit for multiple angles of incidence are shown in Figure S1. The optical constants were further verified by experimentally measuring the transmittance and reflectance of the thin film (see Figure 1e,f) and comparing with the transmittance and reflectance curves simulated using a transfer matrix method, with inputs of film thickness and optical constants taken from SEM and ellipsometry, respectively. The luminous transmittance $T_{\text {lum }}$ and solar transmittance modulation $\Delta T_{\text {sol }}$ of the fabricated thin film are 40.9 and $11.9 \%$, respectively. We note that the fabricated thin film also exhibits the same issue observed in the literature, whereby changes in reflectance and absorption oppose one another, specifically between wavelengths of 600 and $1400 \mathrm{~nm}$ as can be seen from the reflectance spectra in Figure 1f. Specifically, the solar reflectance modulation $R_{\text {sol }}$ is $-4.2517 \%$ (27.04 vs $22.78 \%$ ), which accounts for a loss of $>25 \%$ of the overall solar transmittance modulation.
2.2. Theoretical Limits. In our improved design, a thin film of vanadium dioxide is sandwiched between two transparent impedance matching layers (see Figure 2a), with (a)

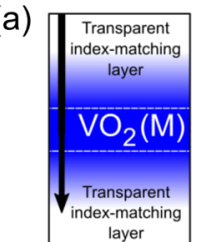

(b)

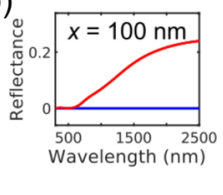

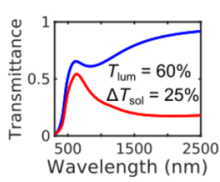

(c)

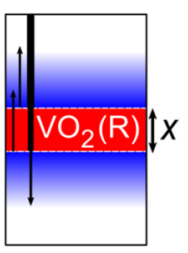

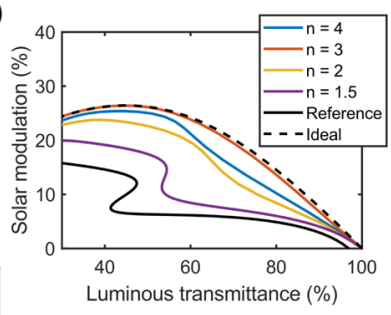

Figure 2. Deriving solar control limits of thin film vanadium dioxide dynamic window coatings: (a) schematic of the idealized design for maximum solar control. (b) Simulated reflectance and transmittance of the idealized structure for $100 \mathrm{~nm}$ thick vanadium dioxide. (c) Derived solar control performance limit at normal incidence when impedance matched from air to $\mathrm{VO}_{2}(\mathrm{M})$ perfectly compared with other nonideal impedance matching from air to $n$ and also for the case of a $100 \mathrm{~nm} \mathrm{VO}$ film on a silica substrate (reference).

the surrounding layers designed to optically impedance match between the low-temperature $\mathrm{VO}_{2}(\mathrm{M})$ state and the surrounding environment. In this case, when in the lowtemperature $\mathrm{VO}_{2}(\mathrm{M})$ state, reflections are minimized across the entire solar spectrum and solar transmittance is maximized. When the thermochromic transition occurs, the impedance matching condition is broken and broad-band increases in reflectance are achieved (see Figure $2 \mathrm{~b}$ ); by matching optical impedance into and out of the thin film in its low-temperature $\mathrm{VO}_{2}(\mathrm{M})$ state, the thermochromic response is utilized beneficially for solar control, regardless of whether the change in refractive index is positive or negative, thereby maximizing solar modulation. Figure $2 \mathrm{c}$ shows this derived theoretical limit (ideal) for a thin film of vanadium dioxide (ranging from 0 to $250 \mathrm{~nm}$ thickness) in comparison with nonideal impedance matched conditions (instead assuming impedance matching from air to $n$ ) and also for a single thin film of vanadium dioxide on a silica substrate (reference). A design approaching 


\section{(a)}

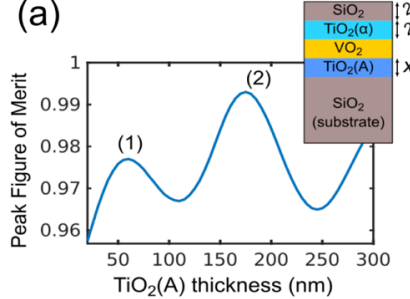

(b)

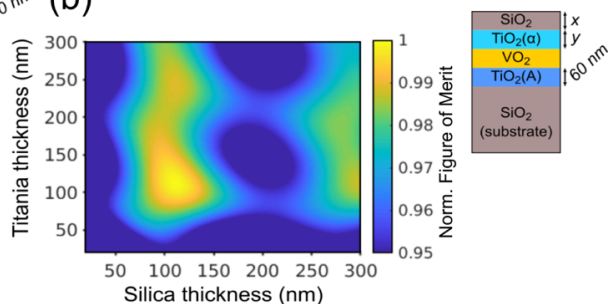

Figure 3. Selection of layer thicknesses: (a) selection of $\mathrm{TiO}_{2}(\mathrm{~A})$ layer thickness. Peak FOM found from full sweep of titania and silica top layer thicknesses $(20-300 \mathrm{~nm})$ as a function of $\mathrm{TiO}_{2}(A)$ layer thickness. First maximum $(60 \mathrm{~nm})$ was chosen because thicker films $(>150 \mathrm{~nm})$ at the second maximum were found to show cracks after annealing. (b) Selection of top silica and titania layers. Peak FOM is found for $100 \mathrm{~nm}$ titania thickness and $110 \mathrm{~nm}$ silica thickness with $\mathrm{TiO}_{2}(\mathrm{~A})$ thickness of $60 \mathrm{~nm}$.

(a)
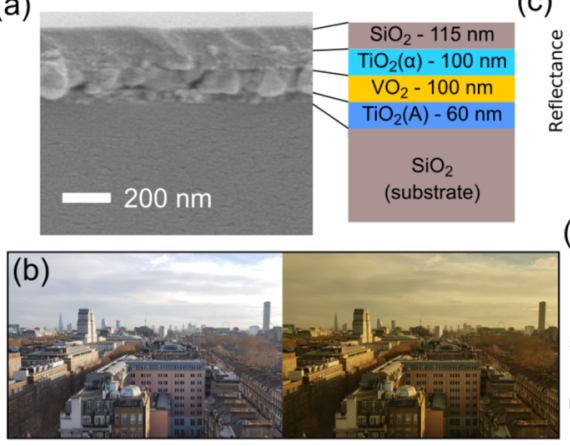

(c)

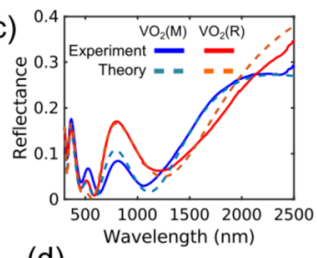

(d)

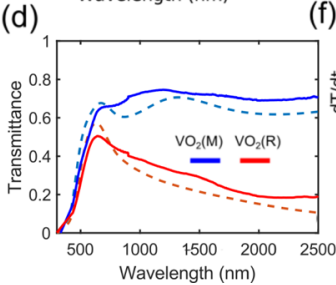

(e)

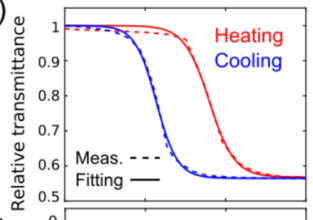

(f)

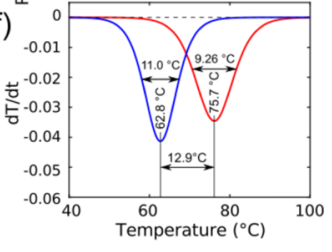

Figure 4. Solution-processed multilayer with record performance: (a) Electron microscopy image of fabricated structure alongside the schematic design. (b) Clear view of London skyline (left) and the same view through the sample in the low-temperature state (right). (c) Spectral reflectance of the fabricated structure compared with simulation. (d) Spectral transmittance of the fabricated structure compared with simulation. (e) Relative transmittance as a function of temperature during heating and cooling. (f) First derivative of relative transmittance as a function of temperature.

the perfect impedance matching limit could conceivably be achieved on industrial scales using a graded-index composite formed via cosputtering, where a high refractive index material would be sputtered simultaneously with a low-refractive-index material. The deposition rates of the two materials could then be varied to achieve a gradient index in-depth; ${ }^{35}$ however, in this work, we use a simpler multilayer structure with a few layers as a proof-of-concept.

\section{MULTILAYER COATING}

If we restrict our impedance matching condition to shorter wavelengths where solar irradiance is the highest (400-1000 $\mathrm{nm}$ ), it can largely be achieved using thin film interference effects with only a few layers and, as we demonstrate here, provide great improvements to solar modulation. The materials used are chosen both for their optical properties (see Figure S2) and because of their well-established viability in the window coating industry. The top two silica $\left(\mathrm{SiO}_{2}\right)$ and titania $\left[\mathrm{TiO}_{2}(\alpha)\right]$ layers have refractive indices $\left(n_{\mathrm{D}}=1.41\right.$ and 1.89 , respectively) ranging between that of air and $\mathrm{VO}_{2}(\mathrm{M})$ and so are able to effectively impedance match between air and $\mathrm{VO}_{2}(\mathrm{M})$, provided that appropriate thicknesses are chosen. The bottom layer is a crystalline anatase titania $\left[\mathrm{TiO}_{2}(\mathrm{~A})\right]$ layer (see Figure S3 for crystallography and Raman analysis) with a refractive index $\left(n_{\mathrm{D}}=2.08\right)$ between that of the fused silica substrate $\left(n_{\mathrm{D}}=1.43\right)$ and $\mathrm{VO}_{2}(\mathrm{M})$, with the layer thickness also chosen such that optical impedance is matched between $\mathrm{VO}_{2}(\mathrm{M})$ and the silica substrate.
To determine the optimum thicknesses, a transfer matrix method was used to simulate the solar modulation $\Delta T_{\text {sol }}$ and luminous transmittance $T_{\text {lum }}$ of the structure. The vanadium dioxide layer thickness was held constant at $100 \mathrm{~nm}$ as this was expected to transmit $>50 \%$ visible light; for greater visible transmittance, the thickness can be reduced at the cost of solar modulation as shown in Figure 2c. The surrounding impedance matching layers were varied in thickness between 20 and $300 \mathrm{~nm}$. The maximum $\Delta T_{\text {sol,max }}$ and $T_{\text {lum, max }}$ from the parameter sweep were found to be 22.4 and 59.7\%, respectively, however these respective optimum values occur for different thickness structures so a compromise is required. A figure of merit (FOM) is calculated to find structures that are able to compromise between the two performance metrics as defined by

$$
\mathrm{FOM}=\left(\frac{\Delta T_{\text {sol }}}{\Delta T_{\text {sol,max }}}+\frac{T_{\text {lum }}}{T_{\text {lum, max }}}\right) / 2
$$

In Figure 3a, the peak FOM found from a full sweep of titania and silica top layer thicknesses $(20-300 \mathrm{~nm})$ is given as a function of $\mathrm{TiO}_{2}$ (A) layer thickness. A $60 \mathrm{~nm}$ thick $\mathrm{TiO}_{2}(\mathrm{~A})$ was chosen since thicker films $(>150 \mathrm{~nm})$ at the second maximum were found to show cracks after annealing. Figure $3 \mathrm{~b}$ shows the $\mathrm{FOM}$ for a $\mathrm{TiO}_{2}(\mathrm{~A})$ layer thickness of $60 \mathrm{~nm}$ as a function of titania and silica top layer thicknesses (20-300 $\mathrm{nm})$. The maximum FOM is found for $100 \mathrm{~nm}$ titania thickness and $110 \mathrm{~nm}$ silica thickness with $60 \mathrm{~nm} \mathrm{TiO}_{2}(\mathrm{~A})$ thickness. 
In Figure 4a a schematic of our optimized design is shown alongside an electron microscopy image of the fabricated structure. Figure $4 \mathrm{~b}$ shows the London skyline unobstructed (left) and also as seen through the sample in its lowtemperature state (right). The view has a golden tint that is characteristic of the optical absorption band of $\mathrm{VO}_{2}(\sim 500$ $\mathrm{nm})$. However, previous works have shown that the optical absorption band can be raised via doping to achieve a more neutral color. ${ }^{36}$ Importantly, there is no haze seen in the image, which is further evidenced via full optical characterization of transmittance haze across the visible range (see Figure S4). Figure $4 \mathrm{c}, \mathrm{d}$ shows that the measured reflectance and transmittance spectra of the fabricated multilayer stack match well with simulation for both low-temperature and hightemperature states. The solar transmittance modulation of the measured spectra is $21.8 \%$, and the visible transmittance is 48.9\% (see Figure 5 for comparison with literature and our

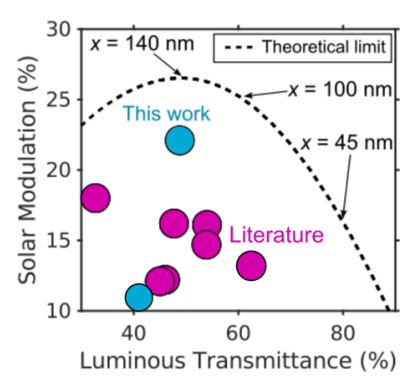

Figure 5. Optical performance comparison between the highperformance multilayer and single thin film coatings demonstrated in this work alongside other multilayer thin film coatings that have previously been demonstrated in the literature.

single $\mathrm{VO}_{2}$ thin film). Additionally, the hysteresis width and gradient width (see Figure $4 \mathrm{f}$ ) of the fabricated structure are both narrow (12.9 and $10.1{ }^{\circ} \mathrm{C}$, respectively), which is critical to the overall energy saving performance. ${ }^{32-34}$ The transition temperature of the coating is $69.3{ }^{\circ} \mathrm{C}$, which is typical for undoped $\mathrm{VO}_{2}$; since titanium doping has been widely reported to raise the transition temperature of $\mathrm{VO}_{2}$, we can infer that there was no significant diffusion of titanium ions into the $\mathrm{VO}_{2}$ layer during the fabrication process.

\section{CONCLUSIONS}

In summary, we have shown theoretically that the optical performance limits of thermochromic vanadium dioxide window coatings are significantly higher than previously reported. We have subsequently used our theoretical observations to experimentally demonstrate a simple multilayer structure that has solar modulation far greater than any inorganic thin film thermochromic coating (>30\% greater than current state-of-the-art $\left.{ }^{24}\right)$ while maintaining a high degree of visible transparency $(48.9 \%)$ and a narrow hysteresis $\left(12.9^{\circ} \mathrm{C}\right)$ and gradient width $\left(10.1{ }^{\circ} \mathrm{C}\right)$. The additional materials used are common within the glass coating industry, and thin film fabrication methods are highly scalable. Therefore, once combined with metal ion doping to optimize the transition temperature, ${ }^{37}$ we anticipate that this design methodology will yield an optimal dynamic window coating highly viable for real-world application. Finally, the theoretical limit derived in this work shows that despite vanadium dioxide proposed as a dynamic window coating material over 30 years ago, the state- of-the-art is far from mature, with great room for innovation, and much more work still needs to be done.

\section{METHODS AND MATERIALS}

5.1. Synthesis of Spin Coating Solutions. The vanadium(IV) and silica solutions were synthesized following the methods described in our previous work. ${ }^{31}$ For the titania solution, a solution of titanium(IV) isopropoxide (TTIP) (Sigma-Aldrich, >97\%), anhydrous isopropanol (IPA), and acetic acid $\left(\mathrm{CH}_{3} \mathrm{COOH}\right)$ (SigmaAldrich, $>99.5 \%$ ) was kept stirring for $0.5 \mathrm{~h}$ and used soon after. The volume ratios of the reactants were as follows: (TTIP/IPA/ $\left.\mathrm{CH}_{3} \mathrm{COOH}=1: 5: 0.4\right)$.

5.2. Fabrication of Thin Films. The spin solutions were uniformly cast onto 2 in. fused silica substrates by spin coating at a range of spin speeds for $30 \mathrm{~s}$ (SCS G3 Spin Coater). All spin-cast films were aged in a box furnace at $100{ }^{\circ} \mathrm{C}$ for $10 \mathrm{~min}$ to remove any remaining solvent. The subsequent heat treatments varied for each desired material. Amorphous titania $\mathrm{TiO}_{2}(\alpha)$ and silica $\mathrm{SiO}_{2}$ were obtained by heating in a box furnace at $150{ }^{\circ} \mathrm{C}$ for a further $1 \mathrm{~h}$; anatase titania $\mathrm{TiO}_{2}(\mathrm{~A})$ was obtained by annealing in a tube furnace at $550{ }^{\circ} \mathrm{C}$ in air for $1 \mathrm{~h}$, whereas monoclinic $\mathrm{VO}_{2}$ was obtained by annealing in a tube furnace at $550^{\circ} \mathrm{C}$ for $1 \mathrm{~h}$ under vacuum $(p<20$ mbar). The tube furnace was ramped up to and down from the set temperature at a ramp rate of $20{ }^{\circ} \mathrm{C} / \mathrm{min}$. Raman and X-ray diffraction (XRD) analysis showing the crystal phases within the sample are shown in Figure S4.

5.3. Material Characterization. XRD measurements were performed using a Bruker-AXS D8 (GADDS) diffractometer. SEM was carried out using a FEI Inspect F microscope with a field emission gun. Raman spectroscopy was performed using an inVia confocal Raman microscope with laser power set to $1 \%$ to avoid sample heating. Optical constants of all materials used were measured using a Semilab SE-2000 spectroscopic ellipsometer (see Supporting Information). The optical constants for $\mathrm{VO}_{2}(\mathrm{M})$ and $\mathrm{VO}_{2}(\mathrm{R})$ were measured at room temperature and at $90{ }^{\circ} \mathrm{C}$, respectively.

5.4. Performance Characterization. Thermochromic properties of the films were tested by measuring their transmittance and reflectance spectra. In order to remove any contribution of the substrate, a plain fused silica sample was measured as a background reference. The luminous transmittance $T_{\text {lum }}$ and the solar modulation $\Delta T_{\text {sol }}$ are defined by

$$
\begin{aligned}
& T_{\text {lum }, \text { sol }}=\frac{\int \phi_{\text {lum }, \text { sol }}(\lambda) T(\lambda) \mathrm{d} \lambda}{\int \phi_{\text {lum }, \text { sol }}(\lambda) \mathrm{d} \lambda} \\
& \Delta T_{\text {sol }}=T_{\text {sol,cold }}-T_{\text {sol,hot }}
\end{aligned}
$$

with the integrals taken between wavelengths $(\lambda)$ of 300 and 2500 $\mathrm{nm} ; \phi_{\text {lum }}(\lambda)$ is the photoscopic spectral sensitivity of human vision ${ }^{38}$ and $\phi_{\text {sol }}(\lambda)$ is the AM 1.5 solar irradiance spectrum. The samples were heated in situ using an aluminum high-temperature cell controlled by a Eurotherm temperature controller and a T-type thermocouple. The hysteresis measurements were performed following the method described in our previous work. ${ }^{31}$ The scattering behavior of the films was measured in transmission using a Radiant Zemax Imaging Sphere for Scatter and Appearance Measurement, where samples were illuminated at a normal angle of incidence at $50 \mathrm{~nm}$ wavelength intervals between 400 and $700 \mathrm{~nm}$ wavelengths. The skyline image through the sample was taken using a Samsung Galaxy S7, with exposure and focus values set automatically without the presence of the sample and held constant for the subsequent measurement through the sample.

5.5. Simulations. Simulations of multilayer transmittance and reflectance were performed using a transfer matrix code written in MATLAB, with material properties for each material derived from ellipsometry. 


\section{ASSOCIATED CONTENT}

\section{(s) Supporting Information}

The Supporting Information is available free of charge at https://pubs.acs.org/doi/10.1021/acsami.9b18920.

Characterization of visible transmittance haze and optical constants, material characterizations such as ellipsometry, XRD, and Raman spectroscopy, and additional electron microscopy images (PDF)

\section{AUTHOR INFORMATION}

\section{Corresponding Author}

Ioannis Papakonstantinou - Photonic Innovations Laboratory, Department of Electronic \& Electrical Engineering, University College London, London WC1E 7JE, U.K.;

Email: i.papakonstantinou@ucl.ac.uk

\section{Authors}

Christian Sol - Photonic Innovations Laboratory, Department of Electronic \& Electrical Engineering, University College

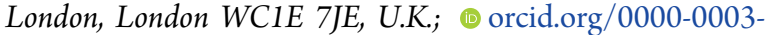
2297-6920

Mark Portnoi - Photonic Innovations Laboratory, Department of Electronic \& Electrical Engineering, University College London, London WC1E 7JE, U.K.

Tao Li - Photonic Innovations Laboratory, Department of Electronic \& Electrical Engineering, University College London, London WC1E 7JE, U.K.; (1) orcid.org/0000-0001-71292184

Kargal L. Gurunatha - Photonic Innovations Laboratory, Department of Electronic \& Electrical Engineering, University College London, London WC1E 7JE, U.K.

Johannes Schläfer - Photonic Innovations Laboratory, Department of Electronic \& Electrical Engineering, University College London, London WC1E 7JE, U.K.

Stefan Guldin - Department of Chemical Engineering, University College London, London WC1E 7JE, U.K.; (1) orcid.org/0000-0002-4413-5527

Ivan P. Parkin - Department of Chemistry, University College London, London WC1H OAJ, U.K.

Complete contact information is available at: https://pubs.acs.org/10.1021/acsami.9b18920

\section{Notes}

The authors declare no competing financial interest.

\section{ACKNOWLEDGMENTS}

This research was supported by the Horizon $\mathrm{H} 2020$ EENSULATE-grant agreement no. 723868 and by the European Research Council (ERC) IntelGlazing, Project ID: 679891. C.S. acknowledges support from the EPSRC Centre for Doctoral Training in Integrated Photonic and Electronic Systems (IPES) (EP/L015455/1).

\section{REFERENCES}

(1) Rogelj, J.; Luderer, G.; Pietzcker, R. C.; Kriegler, E.; Schaeffer, M.; Krey, V.; Riahi, K. Energy system transformations for limiting end-of-century warming to below $1.5^{\circ} \mathrm{C}$. Nat. Clim. Change 2015, 5, 519.

(2) Solomon, S.; Qin, D.; Manning, M.; Averyt, K.; Marquis, M. Climate Change 2007-The Physical Science Basis: Working Group I Contribution to the Fourth Assessment Report of the IPCC; Cambridge University Press, 2007; Vol. 4.
(3) Omer, A. M. Energy, Environment and Sustainable Development. Renewable Sustainable Energy Rev. 2008, 12, 2265-2300.

(4) Granqvist, C. G. Spectrally Selective Coatings for Energy Efficiency and Solar Applications. Phys. Scr. 1985, 32, 401.

(5) Granqvist, C. G. Recent Progress in Thermochromics and Electrochromics: A Brief Survey. Thin Solid Films 2016, 614, 90-96.

(6) Wang, Y.; Runnerstrom, E. L.; Milliron, D. J. Switchable Materials for Smart Windows. Annu. Rev. Chem. Biomol. Eng. 2016, 7, 283-304.

(7) Long, S.; Cao, X.; Li, N.; Xin, Y.; Sun, G.; Chang, T.; Bao, S.; Jin, $\mathrm{P}$. Application-Oriented VO2 Thermochromic Coatings with Composite Structures: Optimized Optical Performance and Robust Fatigue Properties. Sol. Energy Mater. Sol. Cells 2019, 189, 138-148.

(8) Wang, S.; Liu, M.; Kong, L.; Long, Y.; Jiang, X.; Yu, A. Recent Progress in VO2 Smart Coatings: Strategies to Improve the Thermochromic Properties. Prog. Mater. Sci. 2016, 81, 1-54.

(9) Chang, T.-C.; Cao, X.; Bao, S.-H.; Ji, S.-D.; Luo, H.-J.; Jin, P. Review on Thermochromic Vanadium Dioxide based Smart Coatings: from lab to commercial application. Adv. Manuf. 2018, 6, 1-19.

(10) Warwick, M. E. A.; Binions, R. Advances in Thermochromic Vanadium Dioxide Films. J. Mater. Chem. A 2014, 2, 3275-3292.

(11) Manning, T. D.; Parkin, I. P.; Pemble, M. E.; Sheel, D.; Vernardou, D. Intelligent Window Coatings: Atmospheric Pressure Chemical Vapor Deposition of Tungsten-doped Vanadium Dioxide. Chem. Mater. 2004, 16, 744-749.

(12) Granqvist, C. G. Window Coatings for the Future. Thin Solid Films 1990, 193-194, 730-741.

(13) Faucheu, J.; Bourgeat-Lami, E.; Prevot, V. A Review of Vanadium Dioxide as an Actor of Nanothermochromism: Challenges and Perspectives for Polymer Nanocomposites. Adv. Eng. Mater. 2019, 21, 1800438.

(14) Jin, P.; Tanemura, S. $\mathrm{V}_{1-\mathrm{x}} \mathrm{Mo}_{\mathrm{x}} \mathrm{O}_{2}$ thermochromic films deposited by reactive magnetron sputtering. Thin Solid Films 1996, 281-282, 239-242.

(15) Jin, P.; Tanemura, S. Formation and Thermochromism of VO2 Films Deposited by RF Magnetron Sputtering at Low Substrate Temperature. Jpn. J. Appl. Phys., Part 1 1994, 33, 1478.

(16) Parkin, I. P.; Manning, T. D. Intelligent Thermochromic Windows. J. Chem. Educ. 2006, 83, 393.

(17) Binions, R.; Piccirillo, C.; Palgrave, R. G.; Parkin, I. P. Hybrid Aerosol Assisted and Atmospheric Pressure CVD of Gold-Doped Vanadium Dioxide. Chem. Vap. Deposition 2008, 14, 33-39.

(18) Blackman, C. S.; Piccirillo, C.; Binions, R.; Parkin, I. P. Atmospheric Pressure Chemical Vapour Deposition of Thermochromic Tungsten Doped Vanadium Dioxide Thin Films for Use in Architectural Glazing. Thin Solid Films 2009, 517, 4565-4570.

(19) Kozlov, V.; Yadin, E.; Taiminsh, G.; Fomin, V. New Vacuum Equipment for Multilayer Coating Deposition on Large Area Glass. Proceedings of the Annual Technical Conference; Society of Vacuum Coaters, 2007; p 230.

(20) Gordon, R. Chemical Vapour Deposition of Coatings on Glass. J. Non-Cryst. Solids 1997, 218, 81-91.

(21) Currie, M.; Mastro, M. A.; Wheeler, V. D. Characterizing the Tunable Refractive Index of Vanadium Dioxide. Opt. Mater. Express 2017, 7, 1697-1707.

(22) Liu, C.; Wang, S.; Zhou, Y.; Yang, H.; Lu, Q.; Mandler, D.; Magdassi, S.; Tay, C. Y.; Long, Y. Index-tunable Anti-reflection Coatings: Maximizing Solar Modulation Ability for Vanadium Dioxide-based Smart Thermochromic Glazing. J. Alloys Compd. 2018, 731, 1197-1207.

(23) Sol, C.; Schläfer, J.; Li, T.; Guldin, S.; Parkin, I. P.; Papakonstantinou, I. A Combined Experimental and Theoretical Study into the Performance of Multilayer Vanadium Dioxide Composite Films for Energy Saving Applications. Photonics for Solar Energy Systems VII; SPIE, 2018; p 106880D.

(24) Chang, T.; Cao, X.; Dedon, L. R.; Long, S.; Huang, A.; Shao, Z.; Li, N.; Luo, H.; Jin, P. Optical Design and Stability Study for Ultrahigh-Performance and Long-lived Vanadium Dioxide-based Thermochromic Coatings. Nano Energy 2018, 44, 256-264. 
(25) Chang, T.; Cao, X.; Li, N.; Long, S.; Gao, X.; Dedon, L. R.; Sun, G.; Luo, H.; Jin, P. Facile and Low-temperature Fabrication of Thermochromic Cr2O3/VO2 Smart Coatings: Enhanced Solar Modulation Ability, High Luminous Transmittance and UV-Shielding Function. ACS Appl. Mater. Interfaces 2017, 9, 26029-26037.

(26) Mlyuka, N. R.; Niklasson, G. A.; Granqvist, C. G. Thermochromic Multilayer Films of $\mathrm{VO} 2$ and $\mathrm{TiO} 2$ with Enhanced Transmittance. Sol. Energy Mater. Sol. Cells 2009, 93, 1685-1687.

(27) Zhao, Y.; Xu, R.; Zhang, X.; Hu, X.; Knize, R. J.; Lu, Y. Simulation of smart windows in the $\mathrm{ZnO} / \mathrm{VO}_{2} / \mathrm{ZnS}$ Sandwiched Structure with Improved Thermochromic Properties. Energy Build. 2013, 66, 545-552.

(28) Li, S.-Y.; Niklasson, G. A.; Granqvist, C. G. Nanothermochromics: Calculations for $\mathrm{VO}_{2}$ nanoparticles in dielectric hosts show much improved luminous transmittance and solar energy transmittance modulation. J. Appl. Phys. 2010, 108, 063525.

(29) Zhu, J.; Zhou, Y.; Wang, B.; Zheng, J.; Ji, S.; Yao, H.; Luo, H.; Jin, P. Vanadium Dioxide Nanoparticle-based Thermochromic Smart Coating: High Luminous Transmittance, Excellent Solar Regulation Efficiency, and Near Room Temperature Phase Transition. ACS Appl. Mater. Interfaces 2015, 7, 27796-27803.

(30) Chen, Z.; Gao, Y.; Kang, L.; Cao, C.; Chen, S.; Luo, H. Fine Crystalline VO2 Nanoparticles: Synthesis, Abnormal Phase Transition Temperatures and Excellent Optical Properties of a Derived VO2 Nanocomposite Foil. J. Mater. Chem. A 2014, 2, 2718-2727.

(31) Schläefer, J.; Sol, C.; Li, T.; Malarde, D.; Portnoi, M.; Macdonald, T. J.; Laney, S. K.; Powell, M. J.; Top, I.; Parkin, I. P.; et al. Thermochromic $\mathrm{VO} 2-\mathrm{SiO} 2$ nanocomposite smart window coatings with narrow phase transition hysteresis and transition gradient width. Sol. Energy Mater. Sol. Cells 2019, 200, 109944.

(32) Sol, C.; Schläfer, J.; Parkin, I. P.; Papakonstantinou, I. Mitigation of Hysteresis due to a Pseudo-photochromic Effect in Thermochromic Smart Window Coatings. Sci. Rep. 2018, 8, 13249.

(33) Warwick, M. E. A.; Ridley, I.; Binions, R. The Effect of Transition Gradient in Thermochromic Glazing Systems. Energy Build. 2014, 77, 80-90.

(34) Warwick, M. E. A.; Ridley, I.; Binions, R. The Effect of Variation in the Transition Hysteresis Width and Gradient in Thermochromic Glazing Systems. Sol. Energy Mater. Sol. Cells 2015, 140, 253-265.

(35) Schubert, M. F.; Mont, F. W.; Chhajed, S.; Poxson, D. J.; Kim, J. K.; Schubert, E. F. Design of Multilayer Antireflection Coatings made from Co-sputtered and Low-Refractive-Index Materials by Genetic Algorithm. Opt. Express 2008, 16, 5290-5298.

(36) Li, S.-Y.; Mlyuka, N. R.; Primetzhofer, D.; Hallén, A.; Possnert, G.; Niklasson, G. A.; Granqvist, C. G. Bandgap Widening in Thermochromic Mg-doped VO2 Thin Films: Quantitative Data based on Optical Absorption. Appl. Phys. Lett. 2013, 103, 161907.

(37) Manning, T. D.; Parkin, I. P.; Pemble, M. E.; Sheel, D.; Vernardou, D. Intelligent Window Coatings: Atmospheric Pressure Chemical Vapor Deposition of Tungsten-doped Vanadium Dioxide. Chem. Mater. 2004, 16, 744-749.

(38) Sharpe, L. T.; Stockman, A.; Jagla, W.; Jägle, H. A luminous efficiency function, $\mathrm{V}^{*}(\lambda)$, for daylight adaptation. J. Vis. 2005, 5, 3. 